\title{
Making Tomorrow's Leaders Today: Bringing the Real World into the Classroom
}

\author{
${ }^{1}$ Norita Ahmad, ${ }^{2}$ Jenifah Abu Hasan \\ ${ }^{1}$ American University of Sharjah, \\ ${ }^{2}$ Sharjah, United Arab Emirates
}

\begin{abstract}
Our research work elaborates a method called the IDEAS Method [1] on how to teach creative problem solving and other skills related to innovation to college students in order to prepare them for fast paced workplaces. We discuss the context of the problem, review existing research on the topic, and share our learning objectives and stories on how we approach this topic through exercises, assignments, class activities and other resources. We demonstrate by utilizing two different settings. The first example is the application of the method in the business school particularly in the Management Information Systems (MIS) course. The second example is within the English as a Second Language (ESL) classroom. The main contribution of this research is to close the gap between the creative skills of a workforce and the need to produce innovative new products and services. The problem is that we are not educating people that enter organizations to be creative, nor are we training them adequately once they get there. There is a gap between educational organization and the workforce with regard to creative skill building. This however, can be rectified in the classroom. The IDEAS approach can play a huge role in establishing innovative, proactive, contributing individuals ready for the workforce
\end{abstract}

\section{Introduction}

"It is the supreme art of the teacher to awaken joy in creative expression and knowledge" - Albert Einstein

Creative problem solving (CPS) is a powerful teaching method that has been around for quite some time. The literature in education has provided significant evidence on the role of CPS to the advancement of creativity in education e.g. [2]-[5]. A variety of CPS frameworks were proposed such as the original Osborn CPS framework [6] to today's new and improved CPS models [7]-[9]. Academicians such as Torrance, dedicated his entire lifetime to advocate creativity in education [10],[11]. His work ultimately led to the development of the Torrance tests and gifted programs that focuses on explicit teaching of creativity. Creativity expert, Sir Ken Robinson argued that current school systems suppress creativity and leave little room for divergent thinking. In his famous Ted Talk in 2006 [12], Robinson openly said much of the blame for a lack of creativity was on our traditional educational systems. Our educational systems focus on teaching to the correct answer and rely on the external entities such as consulting firms and training centers for practice of creative methods. Today, in 2017, not much has changed since 1950s, when Torrance first proposed his CPS model. In a recent article that appeared in the Guardian [13], thirty eminent academics from the world of neuroscience, education and psychology wrote a letter to the Guardian voicing their concern about the popularity of the 'learning style' approach, favoring instead evidence based practice. It is interesting that they wrote to the Guardian instead of the Department of Education. In the same article, it cites that 'The Department of Education declined to provide a formal comment ... that it was up to the teachers to decide what they wanted to use in the classrooms." Whether there is merit to their recent finding, it seems that educational systems are in fact the slowest adopters of innovation.

Given our students' rich, and diverse backgrounds, they bring unique perspectives and insights to the classroom. These can potentially create a positive environment where we can explore the various issues surrounding us. Lectures alone just do not work for most students anymore no matter how engaging the instructor is. In order to produce innovative thinkers in the workplace, especially in the high tech sector, students should be encouraged to innovate and to "think outside the box." The focus should be on 
making time for meaningful discussions, interaction, activities and application of content during face-to-face sessions.

In this paper, we will discuss the context of the problem, review existing research on the topic, and share our learning objectives and stories on how we approach this topic through exercises, assignments, class activities and other resources. We will demonstrate by utilizing two different settings. The first example is the application of the IDEAS method [1] in the business school particularly in the Management Information Systems (MIS) course. The second example is within the English as a Second Language (ESL) classroom.

The main contribution of this research is to close the gap between the creative skills of a workforce and the need to produce innovative new products and services. The problem is that we are not educating people that enter organizations to be creative, nor are we training them adequately once they get there. Most students expect to be taught at work; just as they had been taught for the previous 16 years (K-12, plus 4 years in college). They do not realize that employers are not looking for that 3.5 or 4.0 employee, but rather looking for problem-solvers and innovators. There is a gap between educational institutions and the workforce with regard to creative skill building. We strongly believe that the gap can be rectified in the classroom. Explicit learning is defined as an active process for learners to seek out structured information that is presented to them, while implicit learning is a passive process where learners acquire knowledge via exposure and experience [10]. With CPS, both implicit and explicit learning bring the issue of creativity to the forefront.

\section{Background}

Creativity scholars have examined the creation, concept, implementations and evaluation of creativity for decades but there is still lack of adequate precision in the definition of creativity. For example, Torrance, one of the pioneers in the field, preferred a psychometric approach to understanding creativity [14] while more recent scholars such as Sternberg, Kaufmann and Pretz [15] adopted a confluence approach as a basis of their work. There is plentiful research on creativity and its application in education [2]-[5],[16], however, actual implementation is rarely achieved [17]. Csikzentmihalyi [16] explained that creative thinking should be shared and tested in socially supportive atmospheres such as the classrooms. In addition, he also suggested that creativity should be viewed as a skill that can be taught. Therefore, as educators, our job is to find ways to encourage and promote creativity in order to prepare students for future job markets. In today's competitive market, students must be innovative and able to use their strengths to find new ways of solving a problem. As such, in this paper, we focus on the IDEAS method that is predicated in a constructivist approach to learning, i.e. learners as active participants in the learning process. Figure 1 shows the IDEAS method learning process.

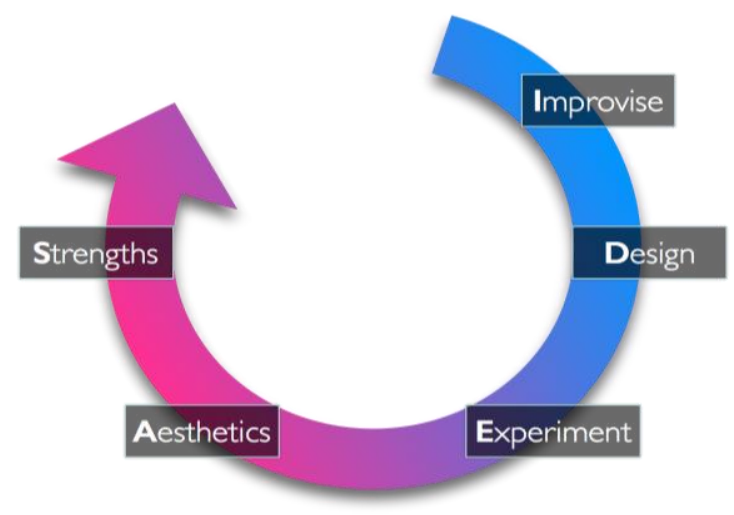

Figure 1. The IDEAS method Learning Process

IDEAS stand for Improvisation, Design, Experimentation, Aesthetics and Strengths [1].

- Improvisation is about the ability to make effective real-time decisions in any given situations. Anything can be the basis for an improvisation however in order to be effective, the improviser must have a set of knowledge that matches the context. For example, comedians often draw their shows from their own experiences, use cues from the audience and their fellow performers to craft a coherent narrative that entertains along the way. They make improvising look easy. But improvisation is the least understood skill in business.

- Stein [1] defined design as "the ability to envision and construct an object or process that meets the goals and requirements of a particular user." In other word, design can be found in a variety of fields, including music, architecture, engineering, literature and software. Design is about learning a language and applying it to the creation of new processes and artifacts.

- Experimentation is often associated with scientific discovery. It begins with the design of an experiment. Experiment can be defined as the process of deciding between two competing goals or viewpoints according to certain criteria. [1] Formal experimental methods are built with more 
time spent in the design of the experiment itself, attention paid to the rigor of the record keeping, and the level and complexity of the analysis. These skills are best acquired through formal training and educational environments.

- Aesthetics is one of the most important factors for evaluating creations from the customers' point of view. It is also the most fundamental component of design. It is commonly defined as "of or pertaining to sensual perception." [18] The working definition that is used in the IDEAS method is "the ability to discriminate between various sensory input, recognize the feelings and thoughts invoked and to rank the object of reflections in terms of certain criteria such as beauty." [1]

- Strength can be defined as "bodily power, force, firmness or moral resistance." [18]. In the context of our study, strength pertained to the multiple intelligences that people possess that can be used for development and creative expression. [1]

The IDEAS method promotes learning through our active interpretation of experience. Sharing that experience with others helps learners to create meaning and to construct models of how the world works.

\section{Methodology}

We will demonstrate the application of the IDEAS method by utilizing two different settings in undergraduate courses at a major American University in United Arab Emirates (UAE). Students come from all over the globe to this private university. As of 2016, the top ten nationalities of all students are as follows: seventeen percent are from the UAE, fourteen percent from Egypt, eleven percent from Jordan, nine percent from India, seven percent from Syria, six percent from Pakistan, four percent from Saudi Arabia, four percent from Palestine, four percent from Lebanon, four percent from the United States of America (USA) and twenty percent from other countries. This represents the global students that are not bound by geographic barriers. In addition, the university consists of a gender balance of male and female students where forty nine point five percent are female and fifty point five percent are male. There are four main schools/colleges in this university, namely School of Engineering, School of Business Administration, College of Arts and Sciences, and the College of Architecture and Design. In addition, there is also a Bridge Program for students who need to enhance their English language to be better prepared for their major since English would be the medium of instruction.
A recent study from Vanderbilt University, USA [19] found that the arts majors developed more creative problem-solving skills than almost any other area of study. It was also mentioned that courses in the art school helped them to develop the skills of risk-taking, dealing with ambiguities, discovering patterns, and the use of analogy and metaphor. Eighty percent of arts students said that expressing creativity was part of their courses; however, only three percent of biology majors and about thirteen percent of engineering and business students reported a focus on creativity in their coursework. Since the majority of the Bridge Program students matriculate into both the Engineering and Business Schools, our focus and case studies will be based on both the Bridge and Business students.

Our first example is the application of the method in the business school particularly in the Management Information Systems (MIS) course. This course provides students with the sociotechnical foundations needed to address the interdisciplinary, integrative, and collaborative aspects of MIS. It focuses on the fundamental principles of problem solving, and the process of change that complements other managerial tools acquired in undergraduate studies.

The course was design with the main goal to make time for meaningful discussions, interaction, activities and application of content during faceto-face sessions. As such, most of the lecture contents from face-to-face class time were moved to before class by assigning them as homework. Technologies such as videos and podcasts, for instance, provide students with the opportunity to learn at their own pace and the freedom to go back and relearn content whenever they want. It also allowed us to spend more time to work with them, to help resolve misconceptions, or difficulties with the lecture content during class.

The course also focused on the leadership and management of creative people and innovation, and hands on learning using a variety of experiential learning processes in simulated teams. Through practice and feedback students developed skills in creative problem solving, and presenting their ideas and opinions rationally. Students benefitted from small-group learning in a collaborative online and face-to-face environment. Specifically, each student had the opportunities to contribute in small groups, received more personal feedback about their ideas and responses, take more ownership of their material, and to think critically about related issues when they work as a team. 
The second example is within the English as a Second Language (ESL) classroom. The Achievement Academy Bridge Program (AABP) is a 'bridge program' that teaches students in the program fifteen hours of English a week to improve their fluency of the language. Students also take a three hour Test Preparatory course to study the Test of English as a Foreign Language (TOEFL) and the International English Language Testing System (IELTS) exams. After getting a minimum score of 80 on the Internet-based TOEFL, or a 550 on the Institutional Paper-based TOEFL, or a score of 6.5 on the academic version of the IELTS, bridge students can then matriculate into their chosen majors.

In addition, students are also enrolled into a University Preparatory course (3 credit hours) where they work on various study skills (notetaking, verbal and PowerPoint presentations, critical thinking, and time-management among others). They also have the choice of signing up for both Math 001 (future Business students take a 3 credit course) and Physics 001 courses. In total, the AABP students would have between 21 to 28 hours in class studies per week.

American Journalist, Sydney J. Harris once wrote, "When most people think of the word "education", they think of a pupil as a sort of animated sausage casing. Into this empty casing, the teachers are supposed to stuff "education". [20] In the ESL classroom, there is this danger; a danger of teaching explicitly (lockstep) since a lot hinges on either internal or external exams. Both teachers and students feel that the outcome of being in these types of programs is for the students to get their required language exam scores and then move on to the next phase - their majors. Students are then 'stuffed' with all the rudimentary to advance lessons for language learning, and test-taking strategies. However, an ESL or Bridge program is the perfect place for students to learn both implicitly as well as explicitly. With the IDEAS method, an ESL instructor can implement implicit well as explicit approaches that foster creativity. "Pupils are more like oysters than sausages. The job of teaching is not to stuff them and then seal them up, but to help them open and reveal the riches within." [20]

IDEAS can help teachers get away from presenting dry class materials. They can avoid banal materials such as grammar or analyzing data by bringing creativity into the classroom setting. IDEAS can reinforce the learning of new concepts for both the ESL students and those who are already in their majors. With this approach, the students should eventually become active participants, not mere listeners and learners who passively get 'stuffed'. After going through the IDEAS approach, these foundation and university students should be more proactive when they matriculate into their majors, and subsequently approach their careers as problem-solvers.

\section{Case study}

In order to develop proficiency and depth for each component of the IDEAS method, we break the process into three processes called 3P: Preparation, Practice and Performance [1] (See Figure 2).

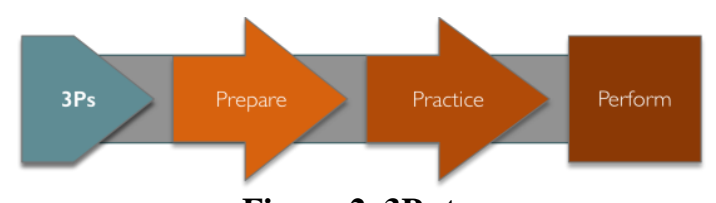

Figure 2.3P steps

In the Preparation step, we focus on exploring basics of the domain through resources such as books, articles, websites, and interviews. All industries from engineering to medicines to automobiles, to space travel are built on scientific principles, and there are no shortage of people to interview about design, experimentation and the scientific method. By talking to people such as musicians, artists, and writers, students get better understanding of improvisation and aesthetics as well.

The Practice step typically involves engaging in small projects that are designed to maximize learning rather than production. For example, in order to practice design thinking, we recommend building with Legos, developing a smart phone application, or designing houses in a virtual world called Second Life. Design is about learning a language and applying it to the creation of new processes and artifacts. For example, the photographer learns the vocabulary of colors and light. The composer learns the vocabulary of sounds. The architect learns the vocabulary of form, function, and materials, and is able to experiment using computer-aided design programs.

The final step of the P3 method is Performance. Performance is about engaging in and sharing new skills with others in a social context. The context of performance can be personal or professional but it has to involve a social context. For example, we can practice a piano concerto by ourselves but needs to perform it live for others to hear. It is therefore important 
to find ways to perform new skills in front of other people. Given the fact that students are now spending more time on social media than ever before, they feel more connected to their classmates (and the instructor) when they use social media. Therefore, we took the opportunity to use social media for student development.

\subsection{Case 1: Employing P3 in the MIS course}

Students who enrolled in this class were juniors or seniors who not only have quite a good understanding of the subject but have a very strong interest in the field as well. As such, we took the opportunity to cover principles, facts and terms as part of out-of-class student preparation and used the classroom time to do the application side where students do hands-on exercises and experience with real-world problems. Through practice and feedback, students develop skills in creative problem solving, and present their ideas and opinions rationally. The following are examples of activities and exercises that were used; corresponding to the three steps in P3 where each of the dimensions of IDEAS method was applied. Figure 3 below shows a matrix of activities and exercises used in this class.

Prepare (P1):

In order to help students understand the concept of improvisation better, we brought in a few guest speakers to the class and encouraged students to interview artists, writers, chefs, art critics, and designers to learn how they employ aesthetic principles to make design choices. We suggested interviewing musicians, comedians, and actors to get a better understanding of performance and improvisation.

\begin{tabular}{|l|c|c|c|} 
& $\begin{array}{c}\text { Prepare } \\
\text { PI }\end{array}$ & $\begin{array}{c}\text { Practice } \\
\text { P2 }\end{array}$ & $\begin{array}{c}\text { Perform } \\
\text { P3 }\end{array}$ \\
\hline $\begin{array}{l}\text { Improvisational } \\
\text { Capacity }\end{array}$ & PI-I & P2-I & P3-I \\
\hline $\begin{array}{l}\text { Design } \\
\text { Proficiency }\end{array}$ & PI-D & P2-D & P3-D \\
\hline $\begin{array}{l}\text { Experimental } \\
\text { Attitude }\end{array}$ & PI-E & P2-E & P3-E \\
\hline $\begin{array}{l}\text { Aesthetic } \\
\text { Awareness }\end{array}$ & PI-A & P2-A & P4-A \\
\hline Strengths & \multicolumn{3}{|c|}{ Multiple Intelligence (MI) } \\
\hline
\end{tabular}

Figure 3. Matrix of activities and exercises used in the class

We also had a skype videoconference with Dr. Eric Stein, the founder of the IDEAS method.
Most of the students hold very limited views of what creative people actually do and found the experience eye opening. Here are some specific examples that we used for each of the dimensions:

- Improvisation: Students were asked to watch the following video: "Improv comedy will change the world" by Jennifer Hunter, TEDxL (https://www.youtube.com/watch?v=LyxHujd RIpk) and "Whose line is it anyway? "(https://www.youtube.com/watch? $\mathrm{v}=\mathrm{mR} 2 \mathrm{I} 4 \mathrm{Z}$ oqpMI). The idea was for the students to understand what it means to improvise, and explore what it means to improvise.

- Design: Students studied the design and innovation at Apple. They took notes of the appearance of iPod, iPhone, iPad and Mac Computers and explored factors that contributed to their popularity.

- Experimental: Students were encouraged to study the history of experimentation and hypothesis testing and watch a series of videos on scientific experiment. Most students feared science and thought it has nothing to do with creativity. In reality, science is one of the most creative endeavors of human mind [1].

- Aesthetic: Students were asked to assess their own perception, emotion, thought and evaluation of their bedroom. They need to ask questions such as: How do I perceive my bedroom? What emotions does my perception of my bedroom create? What thoughts come to mind about my bedroom based o my perceptions and emotions? How would I evaluate my bedroom in terms of aesthetics? Students need to realize that ability to perceive and make aesthetic judgments is as important as learning how to design and improve.

- Strength: Students were assigned to explore Theory of Multiple Intelligences by taking the Multiple Intelligence (MI) profile (https://www.edutopia.org/multiple-

intelligences-assessment) and study the basic principles that it represents. Specifically, areas of strength and areas of development. In order to become good at something, it requires that we spend considerable time developing our talents and abilities [1]. Therefore, one of the first steps is to know our innate talents and strengths. MI is a tool that has been design to assess our cognitive, kinesthetic and perceptual abilities. 
Practice $(\mathrm{P} 2)$

In the practice step, students learn not only the context of the domain but their tolerance for risk, the degrees of self-doubt and self-imposed judgments, and how to work with others in teams.

- Improvisation: Students practice the concept of improvisation with their group members. The focus was on the following: Make a connection, Listen - do not interrupt, Be attentive, $\mathrm{Be}$ in the moment...be flexible, and avoid preconceived ideas and respect other's choices. Each group were then handed a bag that contains random items from around the house. They had to use every item in the bag to create a 1-2 minute skit.

- Design: There are many opportunities for the students to practice design thinking. For example, students were asked to work in pairs, interview one another about their wallet and discuss what they love and hate about it. After the interview process, they were asked to design and build a new wallet for the other person using materials nothing more than paper, tape, markers, scissors, paper clips and the like.

- Experimental: We played a few games such as hang and balance and chairs in class. The objective of this exercise was to illustrate the experimental exercise that we designed for them without telling them in advance. During the game, we observed if men are bigger risktakers than women; if men are more unhappy when they lose; do people take more risk when they play individually vs. in a group?

- Aesthetic: Aesthetic can be in many forms. One of the activities that we did was a blindfolded tactual exploration where students were seated and blindfolded. Each received one object to explore, i.e. explore the movements the object elicits, what we can do with it, and what the object does. After having explored the object in its different aspects, students passed the object to each other one by one until they receive the object they started with. Tactually experiencing without seeing seems to have an exciting aesthetic value in its own right. Especially the fact that the object presents itself immediately in a physical way without visual anticipation is thrilling and confrontational.

- Strength: After taking the MI test, students were encouraged to spend time developing particular intelligence areas that they identified from the test. It is important to note that the measure of strength of a person in a particular intelligence is a measure of their abilities and how much time they spent in that area of knowledge. Students were encouraged to study famous people who represent the same combinations that they identified, specifically: how long did it take them to achieve fame and this skill level? How can they use this information for their own development?

\section{Perform (P3)}

In summary, the best way to practice anything is to do it. Improvisers are real-time designers. They design through performance and action. For example, entrepreneurs improvise products, services and processes, especially in the start-up phase when resources may be scarce. In order to help students perform in public and apply all the basic skills that they acquired throughout the semester, they were asked to do a project called "We are One". The project required students to engage in problem solving on critical social and political issues that affect the school and community by organizing an awareness event on campus. The students had to go through the preparation and practice steps in order to organize such a big event. They learned that no matter how well prepared they were, things could still go wrong. This project helped the students to increase their improvisational capacity, develop their design proficiency, practice experimentation, expand their aesthetic awareness, and leverage their strengths.

In terms of assessing students understanding of the lecture, we asked students to do online quizzes or self-assessments that were not graded. This helped to gauge the students' learning of the material and ensure their understanding of the main concepts covered online and gave students fast and constructive feedback. In addition, the result was also used to properly design in-class activities and group exercises. In terms of graded assessments, we used the following methods:

1. Peer Review/Assessment - By reviewing their peers' work, students consolidate, and deepen both their own and their peers' understanding of the material they learned. This helped students to become comfortable with receiving criticism, justify their own understanding and build critical analysis skills. We also used online discussion board or online document sharing such as a group Dropbox or Google apps in which students all have access to each other's submissions.

2. Class Activities: Usually in groups, where students were required to submit a product of their work for a grade. It will test not only groups' 
readiness/preparedness for class but also individual's readiness/preparedness.

3. Projects and Presentations: Projects were design to give students the chance to go deeper with the material to put the knowledge they have acquired to explore or create something new from it. Every group was required to use online collaboration tool to organize and manage their project, for example, using a tool called Trello. In addition to creating a video, every student was required to present in class.

4. Individual Case analysis: Students had to do 34 cases that include the analysis of companies that illustrates aspects of IDEA's (ImprovisationDesign-Experimentation-Aesthetics) method that we covered in class.

5. Portfolio: Instead of writing a report of their project, students were required to create an online portfolio - a place for them to showcase a collection of their work and reflect on their learning.

\subsection{Case 2: Employing P3 in the ESL class}

One of the tasks in the IELTS exam (Writing: Task 1) is that students have to analyze a table or graph (line, pie, or bar charts) and write a 150word paragraph on it. They have 20 minutes to complete this task. Normally students are familiarized with this task in a very linear way. First, they are taught to study the task and write 10 simple accurate sentences. They are to avoid inaccurate and irrelevant sentences. Then they are given a list of related vocabulary words. For example, they could use increase, decrease, skyrocket, or plummet, when describing a table, chart or graph. Students are given numerous tables and graphs to read, examine and analyze. After a few weeks, they should be able to progress to the much-needed 15 sentences (equaling about 150 words). They work on this exercise at least once a week; study the given task, analyze, and write. A few students wil be able to catch on and by the $5^{\text {th }}$ exercise are begging for something else to do. On the other hand, some students cannot grasp the concept; they simply cannot comprehend how to read the tables and charts. With some students staying in the program for two or even three semesters; how do we avoid these repetition? They lose sight as to the reasons why they should know how to read a chart, and to comprehend graphic data. They do not question why or for what reason such a section is devoted to language learning? This connection (or more likely disconnect) between passing an exam and their future lives are barely discussed. When pointed out that they will probably need to understand charts and graphs in their majors and their future careers, they stop, pause, and might eventually see the connection.

For students to understand the importance of Task 1, the tables are turned on them. They themselves have to generate the charts. The following are examples of activities and exercises that were used; corresponding to the three steps in P3 where each of the dimensions of IDEAS method was applied.

- Prepare: Students are divided into four groups and are then tasked with generating a survey. They have to choose a specific topic. They must improvise a topic for their survey. Some topics chosen after brainstorming among themselves: Exchange Students and their Majors, Favorite Movie Genres, and Favorite Football Leagues. Students then create a 10 question surveys. In order to properly prepare themselves, they need to learn how to design a survey, how to select the participant (they might need to understand some basic definition of experimentation here), how to make their design attractive to the participants and most importantly to understand the strengths that each of them brought to the team.

- Practice: Students then leave the classroom and collect data among their university peers. They must get a minimum of 25 students from both genders and different years (freshmen to seniors) to interview. Then the students have to put their data into a graph of their choice. They can also make tables if they deem necessary. Here the students chose the design of their graphs and tables. They chose the most appropriate graph; pie, line, or bar charts. While working on their individual group task, they start using more vocabulary words pertaining to charts and tables (modest growth, sharp decrease, substantial gain). They not only write these words down, now they are even verbalized get these specific vocabulary words for analyzing a table or graphs. They experiment with different charts and which ones best suit their needs. They also decide whether information in their tables should be designed horizontally or vertically. They must also come up with a key to go with the different information gathered. In addition, students usually chose darker colors for a sizeable amount, and pastel colors when the data is little/or less. At this stage students start to get competitive with their designs, and try to create the most comprehensible and aesthetically attractive charts. Their graphs not 
only have accurate information, but is aesthetically pleasing.

- Perform: Students involve themselves with other students (in class) and outside of class (university wide). They have to work with each other in groups, and later with the rest of the class. They experiment speaking (in public) and interviewing students in their majors. They meet new people and make new friends. After experimenting with different charts and tables, they design them together. Finally they pass their findings to another group, and vice versa. All the 4 groups will then have to write a 150 word paragraph of the charts their peers drew up. After writing their paragraphs, they hand their papers back to the initial group who will verify their analyses.

For assessment, students are given two rubrics to peer review each other's efforts. First, they get a rubric very similar to the IELTS rubric to score their peers' 150 word paragraph (1-9). The second rubric is to give points to the tables and charts that they had generated. They learn to give feedback constructively, and in turn to receive constructive criticism. With four people to a group, they also learn to norm the scores that they give to their peers. By reviewing their classmates' work with rubrics, they get a clearer understanding on how they themselves are graded.

By working in groups, students learn to work with each other and to depend on not only their own strengths, but also each others'. While some students are comfortable doing interviews outside the classroom, others are more comfortable designing the charts. They learn that for the group to be successful, they have to work on their individual and collective strengths.

With this table-turning method, students are able to create and comprehend charts. With this project, their strengths with analyzing charts are honed, and specific vocabulary words are reviewed during their chart making process. The students who initially could not quite grasp the concept of charts and tables get their 'a-ha' moment and can now look at the IELTS: Writing Task 1 from a different perspective.

In summary, by involving students in the process of chart making, we were able to produce a paradigm shift. Students discover that they are the ones in control of the 'problem', and solving it creatively. They are engaged and totally engrossed in their task while debating with each other on the best graphs to use and the tables they need to draw up. They come up with title to their charts, and calculate the percentages. They know they must make a clear (and aesthetically pleasing) chart so that the other groups will be able to interpret the data they input. Students feel a sense of satisfaction when the charts and tables they create are accurately analyze by their peers. By turning the tables on them, and making them the 'creators', students are able to then appreciate the reasoning behind why they are tested on graphs, charts, and tables. They understand that their future endeavors especially in the business school and careers would most likely involve chart and graphs.

\section{Conclusion}

"Imagination is more important than knowledge. For knowledge is limited to all we now know and understand, while imagination embraces the entire world, and all there ever will be to know and understand." - Einstein

Today, when a child, a teen, or a young adult goes off to an educational institution, they expect to be spoon-fed a healthy diet of knowledge and past discoveries. On the first day of class, a college student receives a syllabus, and a list of textbooks to buy. They now feel 'empowered' by these structured tools. These explicit instructional paraphernalia ground them and give them a sense of 'direction'. However, what they are not told is that they should use the greatest tool of all; their brains. They need to think and be prepared to problem-solve during their years in school.

Learning takes place in a variety of ways. We learn through books, by talking to other people, and by doing. Part of learning is about constructing meaning from seemingly disparate data, information, and experience. In this paper, we focus on the IDEAS method that promotes a constructivist approach to learning. Learners from constructivist point of view are not simply passively waiting for information to be given to them. Learning takes place through ones active interpretation of experience. Sharing experience with others helps learners to create meaning and to construct models of how the world works. Therefore, the role of the instructor is to provide opportunities for the students to learn in this way. "Creative teaching is said to increase levels of motivation and self-esteem on the part of learners and to prepare them with the flexible skills they need for the future. Developing the capacity to be creative is believed to have the potential to enrich lives and help contribute to a better society." [19]

While we have to acknowledge that some information needs to be learned via textbooks and 
other educational aids, the reality is that when any students 'matriculate' into the real world of careers, they will no longer be 'taught'. Instead they will be expected to know what to do and perform. The person above them will have a limited time to guide them; therefore they will have to creatively practice problem- solving skills. The boss expects solutions, not more problems. "The whole purpose of education is to turn mirrors into windows. " [20] The role of educators should be to enriched and not restricted to teaching basic fundamentals only. It is important for students to know that creativity is not just for artists, musicians and writers. Everyone has creative talents and can learn the behaviors associated with creativity - creativity is something we are born with. Today we stand on the shoulders of giants. Educators need to remind themselves and their students that creativity is innate. Which books on gravity did Newton study? Which books on aerodynamics did the Wright brothers read? Creativity is within all of us, we just need to have it kindled.

\section{References}

[1] Stein, E. W. (2014). Designing Creative High Power Teams and Organizations: Beyond Leadership. New York: Business Expert Press.

[2] Treffinger, D. J., \& Isaksen, S. G. (2005). Creative problem solving: The history, development, and implications for gifted education and talent development. Gifted Child Quarterly, 49(4), pp. 342353.

[3] Atkinson, R., \& Easthope, H. (2009). The consequences of the creative class: the pursuit of creativity strategies in Australia's cities. International Journal of Urban and Regional Research, 33(1), pp. 6479.

[4] Hill, A. M. (1998). Problem solving in real-life contexts: An alternative for design in technology education. International journal of technology and design education, 8(3), pp. 203-220.

[5] Howard-Jones, P. A. (2002). A dual-state model of creative cognition for supporting strategies that foster creativity in the classroom. International journal of technology and design education, 12(3), 215-226.

[6] Osborn, A. F. (1953/1979). Applied imagination: Principles and procedures of creative problem-solving. New York: Scribner's.

[7] Isaksen, S. G., \& Treffinger, D. J. (1985). Creative problem solving: The basic course. Buffalo, NY: Bearly Limited.
[8] Isaksen, S. G., Dorval, K. B. \& Treffinger, D. J. (1994). Creative approaches to problem solving. Dubuque, IA: Kendall Hunt.

[9] Puccio, G. J., Murdock, M.C., \& Mance, M. (2007). Creative leadership: Skills that drive change. Thousand Oaks, CA: Sage Publications.

[10] Torrance, E. P. (1977). Creativity in the Classroom; What Research Says to the Teacher.

[11] Ellis Paul Torrance (n.d.). In Wikipedia. Retrieved March 1, 2017, from https://en.wikipedia.org/ wiki/Ellis_Paul_Torrance

[12] Robinson, K. (2006, February). Ken Robinson: Do schools kill creativity? [Video file]. Retrieved from https://www.ted.com/talks/ken_robinson_says_schools_ kill_creativity

[13] Weale, S. (2017, March 17). Teachers must ditch 'neuromyth' of learning styles. The Guardian. Retrieved from

https://www.theguardian.com/education/2017/mar/13/te achers-neuromyth-learning-styles-scientists-neuroscience-education

[14]Torrance, E. P. (1974). Torrance tests of creative thinking. Lexington, MA: Personnel Press.

[15] Sternberg, R. J., Kaufman, J. C., \& Pretz, J. E. (2002). The creativity conundrum. New York: Psychology Press.

[16] Csikszentmihalyi, M., \& Wolfe, R. (2014). New conceptions and research approaches to creativity: Implications of a systems perspective for creativity in education. In The systems model of creativity (pp. 161184). Springer Netherlands.

[17] Plucker, J. A., Beghetto, R. A., \& Dow, G. T. (2004). Why isn't creativity more important to educational psychologists? Potentials, pitfalls, and future directions in creativity research. Educational psychologist, 39(2), 83-96.

[18] Harper, D. (2017).http://www.etymonline.com/ index.php?term=aesthetics. Retrieved March 1, 2017, from Online Etymology Dictionary:www.etymonline.com

[19] Richards, J. C. (2013). Creativity in language teaching. Plenary address given at the Summer Institute for English Teacher of Creativity and Discovery in Teaching University Writing. Hong Kong: City University of Hong Kong.

[20] Harris, S. J. (1985). Pieces of Eight Pa. Mariner Books. 